\title{
Exendin-4 ameliorates oxidized-LDL-induced inhibition of macrophage migration in vitro via the NF-KB pathway
}

\author{
Ge-fei MA*, Song CHEN", Lei YIN, Xiang-dong GAO*, Wen-bing YAO* \\ State Key Laboratory of Natural Medicines, School of Life Science and Technology, China Pharmaceutical University, Nanjing 210009, \\ China
}

Aim: To investigate the effects of the glucagon-like peptide-1 (GLP-1) receptor agonist exendin-4 on oxidized low-density lipoprotein (oxLDL)-induced inhibition of macrophage migration and the mechanisms underlying the effects of exendin-4.

Methods: Primary peritoneal macrophages were extracted from the peritoneal cavity of mice treated with $3 \%$ thioglycollate $(2 \mathrm{~mL}$, ip). Migration of the macrophages was examined using a cell migration assay. Macrophage migration-related factors including leptin-like ox-LDL receptor (LOX-1), cyclooxygenase 2 (COX-2), tumor necrosis factor (TNF)- $\alpha$, interleukin-1 (IL-1) $\beta$, matrix metalloproteinase-2 (MMP-2), intercellular adhesion molecule (ICAM)-1 and macrophage migration inhibitory factor (MIF) were measured using semiquantitative RT-PCR. Expression of MIF and ICAM-1 proteins was examined with ELISA. Gelatin zymography was used to evaluate the activity of MMP-9. Activation of the NF-KB pathway was determined by confocal laser scanning microscopy.

Results: Treatment of the macrophages with ox-LDL $(50 \mu \mathrm{g} / \mathrm{mL})$ markedly suppressed the macrophage migration. Furthermore, ox-LDL treatment substantially increased the expression of the macrophage migration-related factors, the activity of MMP-9 and the translocation of the NF-kB p65 subunit. These effects of ox-LDL were significantly ameliorated by pretreatment with the specific NF-kB inhibitor ammonium pyrrolidine dithiocarbamate $(100 \mu \mathrm{mol} / \mathrm{L})$. These effects of ox-LDL were also significantly ameliorated by pretreatment with exendin-4 (25 and $50 \mathrm{nmol} / \mathrm{L})$.

Conclusion: Exendin-4 ameliorates the inhibition of ox-LDL on macrophage migration in vitro, via suppressing ox-LDL-induced expression of ICAM-1 and MIF, which is probably mediated by the NF-KB pathway.

Keywords: macrophage; macrophage migration inhibitory factor; ICAM-1; NF-kB; GLP-1; exendin-4; ox-LDL; ammonium pyrrolidine dithiocarbamate; CD36; atherosclerosis

Acta Pharmacologica Sinica (2014) 35: 195-202; doi: 10.1038/aps.2013.128; published online 16 Dec 2013

\section{Introduction}

Cardiovascular disease (CVD) is an increasingly prevalent diagnosis that is potentially caused by atherosclerosis (AS) ${ }^{[1]}$. AS was related to the accumulation of fatty materials and a chronic inflammatory response to macrophages gathering at the arterial wall ${ }^{[2]}$. Although we do not completely understand the exact mechanism of atherosclerotic progression, previous studies have shown that AS is promoted at the initiation and development stages by an inflammatory response induced by oxidized low-density lipoprotein (ox-LDL) ${ }^{[3,4]}$. OxLDL plays a critical role in limiting the macrophage migration

\footnotetext{
\# These two authors contributed equally to this work.

* To whom correspondence should be addressed.

E-mail wbyao@cpu.edu.cn (Wen-bing YAO) xdgao@cpu.edu.cn (Xiang-dong GAO)

Received 2013-04-08 Accepted 2013-08-12
}

away from the arterial intima and formatting the lipid-laden $\operatorname{code}^{[4]}$. Previous studies on atherosclerotic plaque progression and regression have revealed the dynamic nature of atherosclerotic lesions, the important role of the trapped neointimal macrophages in lesion growth, and macrophage emigration to regional lymph nodes during lesion regression ${ }^{[5,6]}$. However, sufficient understanding on the role of macrophage trapping in the progression of AS is still lacking.

Glucagon-like peptide-1 (GLP-1) is a gut hormone secreted from L-cells and stimulates a glucose-dependent insulin response. Exogenous administration of a GLP-1 receptor agonist, such as exendin- 4 , has been shown to have certain direct beneficial effects on the cardiovascular system ${ }^{[7-9]}$, such as protection against ischemia ${ }^{[10]}$ and improvement of left ventricular performance after myocardial infarction ${ }^{[1,12]}$. Several other studies have reported that exendin- 4 can also affect fatty 
acids effusing into atherosclerotic lesions ${ }^{[11,13]}$. Arakawa et $a l^{[14]}$ found that exendin- 4 could reduce monocyte adhesion by inhibiting the inflammatory response. However, the effects and mechanisms of the GLP-1 receptor agonist exendin- 4 on macrophage migration have not been studied.

Macrophage migration inhibitory factor (MIF) is a lymphokine that prevents random migration of macrophages and recruits macrophages at inflammatory sites ${ }^{[15]}$. MIF has been associated with atherogenesis and the development of metabolic disorders, such as obesity and insulin resistance, when accompanied by other risk factors ${ }^{[16-18]}$. Previous studies have shown that up-regulated MIF mRNA and protein levels may contribute to macrophage accumulation to form the macrophage-rich early fatty streak. MIF has been found in the intima at the initiation stage of atherogenesis ${ }^{[15,19]}$. The NF-kB signaling pathway, as a key transcription factor pathway, is known to mediate inflammation by regulating the expression of cytokines and chemokines. Recent work has revealed the important role of NF-kB in macrophage migration ${ }^{[20]}$. Proteins of the matrix metalloproteinase (MMP) family are involved in the breakdown of the extracellular matrix in normal physiological processes, such as embryonic development, reproduction, and tissue remodeling, as well as in disease processes, such as arthritis, intracerebral hemorrhage, and metastasis ${ }^{[18,}$ ${ }^{21]}$. Symptomatological and histological evidence from recent work has shown that the activity of MMP-9 increases in the unstable carotid plaques in atherogenesis ${ }^{[22]}$. Furthermore, significant increases in the levels of circulating MMP-9 have also been observed in patients with ongoing spontaneous embolization by carotid endarterectomy ${ }^{[23]}$. Intercellular adhesion molecule 1 could mediate macrophage adhesion with the vessel wall, thereby inhibiting migration of macrophages and causing development of atherosclerotic plaques ${ }^{[24]}$. In the present study, we investigated the effect of the GLP-1 receptor agonist exendin- 4 on the ox-LDL-induced inhibition of macrophage migration. We examined the potential mechanisms of ox-LDL, including regulation of MIF and ICAM-1 expression, activity of MMP-9, and the NF-kB pathway.

\section{Materials and methods Materials}

Exendin-4 was obtained from Fang Yuan Pharmaceutical Co, Ltd (Changzhou, China). Matrigel matrix, thioglycollate, PDTC (NF-kB inhibitor) and all antibodies were purchased from Becton Dickinson (Franklin Lakes, NJ, USA). OxidizedLDL was purchased from Yi Yuan Biochemistry Co, Ltd (Guangzhou, China). Lipopolysaccharides (LPS) and monocyte chemotactic protein-1 (MCP-1) were acquired from Sigma (St Louis, MO, USA). DMEM (Dulbecco's modified Eagle's medium), fetal bovine serum (FBS), and penicillin/streptomycin were purchased from Gibco BRL (Grand Island, NY, USA). Trizol reagent was purchased from Invitrogen (Carlsbad, CA, USA). TaKaRa RNA PCR Kit (AMV; version 3.0) was acquired from Takara Biotechnology Co, Ltd (Dalian, China). Proteinase inhibitors and cell lysis buffer were obtained from Cell Signaling Technology Co, Ltd (Trask Ln, Danvers, MA,
USA). EMSA Kit was obtained from Thermo Scientific Co, Ltd (Wyman Street Waltham, MA, USA). BCA protein assay kit and all other chemicals were of analytical or cell-culture grade.

\section{Cell culture}

Thioglycollate-elicited primary mouse peritoneal macrophages were extracted from 7-week-old ICR mice by intraperitoneal lavage, $3 \mathrm{~d}$ after peritoneal injection of $2 \mathrm{~mL} \mathrm{3 \%}$ thioglycollate. The purity of peritoneal macrophages was determined by flow cytometry using an anti-Mac antibody that specifically binds to macrophages. Only cells exhibiting $\geq 95 \%$ purity were used in this study. Macrophages were cultured in DMEM medium containing glucose at the concentration of $4500 \mathrm{mg} / \mathrm{L}$ and supplemented with $10 \%$ FBS, penicillin $(100 \mathrm{U} / \mathrm{mL})$, and streptomycin $(100 \mu \mathrm{g} / \mathrm{mL})$ at $37^{\circ} \mathrm{C}$, with $5 \% \mathrm{CO}_{2}$ and $95 \% \mathrm{O}_{2}$. LPS was used at the concentration of $5 \mu \mathrm{g} / \mathrm{mL}$, and ox-LDL was used at a concentration of $50 \mu \mathrm{g} / \mathrm{mL}$.

\section{RNA extraction and semi-quantitative RT-PCR}

To examine the expression of genes of interest, semi-quantitative RT-PCR analysis was carried out. Total RNA was isolated from macrophages using Trizol, according to the manufacturer's protocol. To analyze the RNA integrity and concentration, samples were analyzed by capillary electrophoresis on an Agilent 2100 BioAnalyzer. RNA was extracted from three independent cultures for each condition, as previously described in detail. The same amount of RNA of each sample was used to make cDNA using the TaKaRa RNA PCR Kit. The cDNA strands for PCR amplification were shown in Table 1.

PCR was performed with a thermocycler using the following cycle parameters: 30 cycles of $94^{\circ} \mathrm{C}$ for $15 \mathrm{~s}, 60^{\circ} \mathrm{C}$ for $15 \mathrm{~s}$, and $72{ }^{\circ} \mathrm{C}$ for $15 \mathrm{~s}$. The amplification products were analyzed in $1.2 \%$ agarose gels. The macrophage GAPDH gene was used as an internal control to verify the absence of significant variation in the cDNA levels in the samples.

\section{Gelatin zymography}

Protein samples were extracted from mouse peritoneal macrophage cultures and were denatured at room temperature for $10 \mathrm{~min}$. Then, the samples were run on an $8 \%$ gelatin gel with an equal volume of electrophoresis sample buffer ${ }^{[22]}$. One microgram of sample was run per lane, with volumes adjusted according to protein concentration. After electrophoresis, the gel was washed three times in $2.5 \%$ Triton X-100 solution with gentle stirring for $0.5 \mathrm{~h}$ at room temperature. The Triton X-100 solution was replaced with developing buffer [Tris-base 12.1 g/L, Tris- $\mathrm{HCl} 63 \mathrm{~g} / \mathrm{L}, \mathrm{NaCl} 117 \mathrm{~g} / \mathrm{L}, \mathrm{CaCl}_{2} 7.4 \mathrm{~g} / \mathrm{L}$, and Brij$350.2 \%(w / v)]$. The gel was then agitated at room temperature for $30 \mathrm{~min}$, moved into fresh developing buffer, and incubated at $37^{\circ} \mathrm{C}$ for $24 \mathrm{~h}$. Finally, the gel was stained with $0.5 \%$ Coomassie-blue and de-stained in a solution containing $5 \%$ methanol and $7 \%$ acetic acid.

\section{ELISA analysis}

A total of $1 \times 10^{6}$ inflammatory macrophage cells were lysed in cell lysis buffer containing proteinase inhibitors and lysates 
Table 1. Semi-quantitative RT-PCR analysis primers.

\begin{tabular}{|c|c|c|}
\hline MMP-2 & CAGGGAATGAGTACTGGGTCTATT & ACTCCAGTTAAAGGCAGCATCTAC \\
\hline IL-1 $\beta$ & CGCAGCAGCACATCAACAAGAGC & TGTCCTCATCCTGGAAGGTCCACG \\
\hline TNF- $\alpha$ & GCAAFCTTCGCTCTTCTGTCTACTGAACTT & GCTCTAGAATGAGATAGCAAATCGGCTGAC \\
\hline COX-2 & GTATCAGAACCGCATTGCCTC & CGGCTTCCAGTATTGAGGAGAACAGAT \\
\hline
\end{tabular}

and stored at $-70^{\circ} \mathrm{C}$ until use. The MIF ELISA was performed using a commercially available paired antibody following the manufacturer's protocols with a detection limit of $16 \mathrm{pg} / \mathrm{mL}$. ELISA plates were coated with mouse anti-MIF or anti-ICAM antibody and stored overnight at $4{ }^{\circ} \mathrm{C}$. The plates were then blocked with PBS containing 1\% BSA and 5\% sucrose for $2 \mathrm{~h}$ at room temperature and then washed with a wash buffer $(0.05 \%$ Tween 20 in PBS). Cell lysates were diluted in Tris-buffer $(0.1 \%$ BSA and $0.05 \%$ Tween 20 in pH 7.3 Tris, 1/200) and incubated overnight at $4{ }^{\circ} \mathrm{C}$. The plates were rinsed in wash buffer and then incubated sequentially with biotinylated goat anti-mouse MIF, goat anti-mouse ICAM-1, and streptavidinHRP (Millipore, Billerica, MA, USA) for $2 \mathrm{~h}$ each at room temperature. After washing, $100 \mathrm{~mL}$ tetramethylbenzidine substrate (Sigma-Aldrich, St Louis, MO, USA) was added to the plates and incubated for 5-10 min. The reaction was stopped with $0.5 \mathrm{~mol} / \mathrm{L} \mathrm{H}_{2} \mathrm{SO}_{4}$. The plates were then analyzed at 450 $\mathrm{nm}$. The total protein concentrations of all lysate samples were determined using the BCA Protein assay kit (Pierce, Rockford, IL, USA). The results are presented as MIF or ICAM-1 protein per milligram total protein.

\section{Cell migration assay}

Peritoneal injections of $1 \mathrm{~mL} \mathrm{4 \%}$ thioglycollate were given to seven-week-old ICR mice, followed by peritoneal injections of ox-LDL $(50 \mu \mathrm{g} / \mathrm{mL}) 72 \mathrm{~h}$ later. One hour after the injection of ox-LDL, LPS $(250 \mu \mathrm{L} ; 5 \mu \mathrm{g} / \mathrm{mL})$ was injected into the mice peritoneum. After $4 \mathrm{~h}, 95 \%$ mouse anti-Mac antibody-positive cells were isolated and collected from the abdominal cavity. The cells were resuspended in DMEM medium containing $10 \% \mathrm{FBS}^{[23]}$. Then, $5 \times 10^{4}$ cells were added to the small upper chamber (with $5 \mu \mathrm{m}$ film) of a transwell. Cells in the control group ( $\mathrm{pH} 7.4 \mathrm{PBS}$ ) and a model group (50 $\mu \mathrm{g} / \mathrm{mL}$ ox-LDL) were added to the upper wells of transwell chambers. The treatment group were pretreated with exendin- 4 at 25 and 50 $\mathrm{nmol} / \mathrm{L}$ for $8 \mathrm{~h}$, and then $50 \mu \mathrm{g} / \mathrm{mL}$ ox-LDL was added in the upper chamber and incubated for another $8 \mathrm{~h}$. Cells in the inhibitor group was pretreated $100 \mu \mathrm{mol} / \mathrm{L}$ PDTC for $8 \mathrm{~h}$ and then $50 \mu \mathrm{g} / \mathrm{mL}$ ox-LDL was added in the upper chamber for $8 \mathrm{~h}$. For the NF-kB agonist group and monocyte chemotactic protein-1 groups, $80 \mu \mathrm{g} / \mathrm{mL}$ PMA and $10 \mathrm{ng} / \mathrm{mL}$ MCP-1, respectively, was added to the lower chamber and incubated at $37^{\circ} \mathrm{C}$ for $8 \mathrm{~h}$. After wiping off the Matrigel matrix and the cells in the upper chamber, $500 \mu \mathrm{L} 0.1 \%$ crystal violet was added to the lower chamber, and the small chamber was placed inside the lower chamber again. The membrane was immersed and incubated at $37^{\circ} \mathrm{C}$ for $30 \mathrm{~min}$ and finally washed with PBS. Three random fields were chosen within the view diameter (magnification $\times 400$ ), and the cells were counted.

\section{Confocal laser-scanner microscopy}

Inflammatory macrophages collected from lavage and an NF- $\mathrm{kB}$ activation nuclear translocation assay kit (Beyotime Institute of Biotechnology, Haimen, China) was used to measure the effect of NF-kB activation. After macrophage cells were fixed and the epitope was blocked, rabbit anti-mouse NF-kB p65 subunit antibody was added to the cells and incubated at $4{ }^{\circ} \mathrm{C}$ overnight. Then, goat anti-rabbit fluorescent antibody and DAPI were added and incubated at room temperature for $1 \mathrm{~h}$. Samples were observed by confocal microscopy.

The inhibitory effect of exendin- 4 on NF-kB DNA binding was determined by Electrophoretic Mobility-Shift Assay (EMSA), as previously described ${ }^{[24]}$. Nuclear extracts were prepared from ox-LDL-treated cells and incubated with a biotin-end-labeled, double-stranded NF-кB consensus oligonucleotide (5'-AGTTGAGGGGACTTTCCCAGGC-3'; Promega, Madison, WI, USA) for $30 \mathrm{~min}$ at room temperature. The binding conditions have been optimized by Shin et al ${ }^{[24]}$. To verify the oligonucleotide's specificity for NF-kB, a 50-fold excess concentration of unlabeled NF- $\mathrm{kB}$ oligonucleotide was added to the reaction mixture as a competitor. For the supershift assay, $1 \mathrm{~mL}$ of the p65 antibodies was added, followed by $30 \mathrm{~min}$ incubation at room temperature. Then, the samples were electrophoresed through $6 \%$ native polyacrylamide gel. Finally, the gel was dried and exposed to X-ray film. The signals obtained from the dried gel were quantified with an FLA3000 apparatus (Fuji, Tokyo, Japan) using BAS reader v 3.14 and Aida v 3.22 software (Fuji-Raytest, Straubenhardt, Germany).

\section{Statistical analysis}

All data are expressed as the mean \pm SEM. Differences between groups were analyzed with Student's $t$-test. Values of $P \leq 0.05$ were considered to represent a statistically significant difference. 


\section{Results}

Exendin-4 enhances the migration of mouse peritoneal macrophages, which is suppressed by ox-LDL

To examine the effect of exendin- 4 on mouse peritoneal macrophage migration, we measured the migration rate of murine macrophages by adopting the method described by Cao et $a l^{[25]}$. Murine macrophages from the peritoneal cavity were induced by LPS $(5 \mu \mathrm{g} / \mathrm{mL})$. Mouse peritoneal macrophages were treated with exendin- 4 at two concentrations (25 and 50 $\mathrm{nmol} / \mathrm{L}$ ) or PDTC $100 \mu \mathrm{mol} / \mathrm{L}$ for $8 \mathrm{~h}$ and were then exposed to ox-LDL $(50 \mu \mathrm{g} / \mathrm{mL})$ for $8 \mathrm{~h}$. The control group contained only ox-LDL $(50 \mu \mathrm{g} / \mathrm{mL})$ and the LPS-induced macrophages. Compared to the control group, the macrophages treated with exendin-4 and PDTC displayed enhanced migration (Figure 1A). The number of migrated cells were counted by inverted microscope (10 visual fields were randomly chosen). The samples pretreated with exendin-4 (25 and $50 \mathrm{nmol} / \mathrm{L})$ and PDTC (100 $\mu \mathrm{mol} / \mathrm{L})$ contained 80, 127, and 105 migrated cells, while the control group contained only 29 migrated cells (Figure 1B). These findings indicate that exendin- 4 enhanced the migration of mouse peritoneal macrophages in vitro, probably by suppressing the activity of NF-kB pathway.

\section{Exendin- 4 suppresses the expression of MIF by affecting the uptake of ox-LDL}

The expression of MIF has been shown to be induced by oxLDL in dose- and time-dependent manners ${ }^{[15]}$. It has been demonstrated that CD36 (a member of the scavenger receptor $\mathrm{B}$ and the ox-LDL cell surface receptor) is implicated in mediating the uptake of ox-LDL and controlling the formation of foam cells in atherogenesis ${ }^{[26]}$. To further investigate the molecular mechanism, by which exendin-4 enhanced migration of mouse peritoneal macrophages, we determined the transcriptional and translational levels of MIF by semi-quantitative RT-PCR analysis and enzyme-linked immunosorbent assay (ELISA). We found that the expression of MIF decreased in the treated group at both transcriptional (Figure 2A) and translational levels (Figure 2B).
The transcriptional levels of CD36, leptin-like ox-LDL receptor (LOX-1), tumor necrosis factor-a (TNF-a), and interleukin-1 $\beta$ (IL-1 $\beta$ ) were measured by semi-quantitative RT-PCR. The expression of CD36, LOX-1, TNF- $\alpha$, and IL-1 $\beta$ decreased markedly in the exendin- 425 and $50 \mathrm{nmol} / \mathrm{L}-$ and PDTC $100 \mu \mathrm{mol} / \mathrm{L}$-treated groups (Figure 2A).

\section{Exendin-4 suppresses the nuclear translocation of NF-kB p65, which may be induced by MIF}

To further explore the intracellular mechanism of exendin- 4 in macrophage migration, we investigated the role of the inflammation-sensitive transcription factor NF-kB. The expression of the NF-kB p65 subunit was determined using semiquantitative RT-PCR. The expression of NF-kB p65 decreased in both exendin-4-treated groups, compared with the control group (Figure 3A). The evidence obtained from the confocal microscopy assay suggests that p65 translocation is greatly reduced in the exendin-4-treated group and the PDTC group, compared to the control group (Figure 3B). Additionally, the EMSA showed that the amounts of DNA and NF-kB complex were limited in the exendin-4-treated group, compared with the control group, and that the band shift was also reduced (Figure 3C). These results indicate that exendin- 4 can inhibit macrophage migration induced by ox-LDL by suppressing NF- $\mathrm{KB}$ p65 expression and NF- $\mathrm{KB}$ protein binding to specific DNA sequences.

\section{Exendin-4 suppresses the activity of MMP-9 and the expression of ICAM-1 and other migration-related factors}

There are certain biomarkers that are directly related to macrophage migration ${ }^{[27]}$ and are potentially regulated by the NF- $\mathrm{kB}$ signaling pathway ${ }^{[28,29]}$. Among these biomarkers, ICAM-1 and MMP-9 play the most important roles as reported in previous studies $^{[30,31]}$. Therefore, we tested the effect of exendin- 4 on the activity of MMP-9 and the expression of ICAM-1 when both were induced by ox-LDL. Compared with the control group, the expression of MMP-9 mRNA (Figure 4A) and activity of MMP-9 (Figure 4B) were remarkably decreased in the
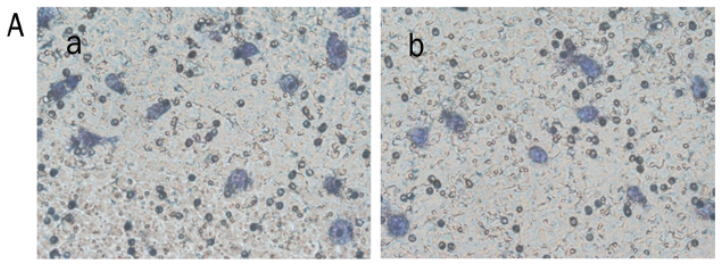

B

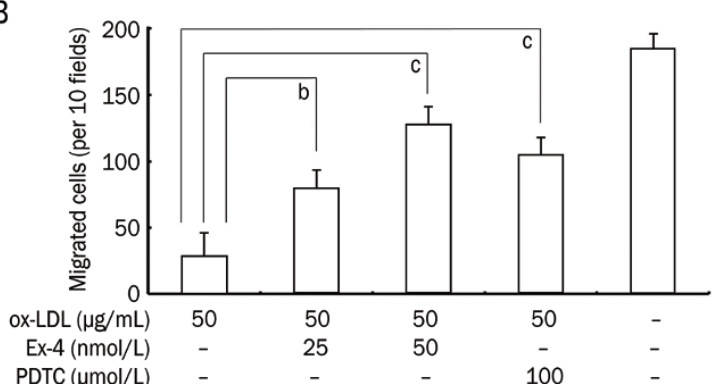

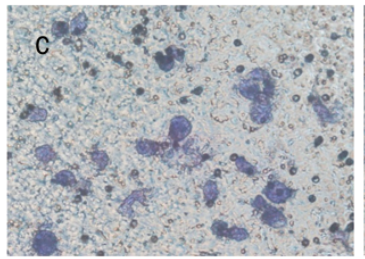
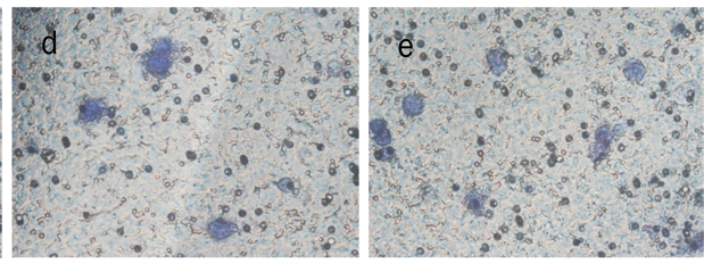

Figure 1. Mouse peritoneal macrophage cell migration assay. Mouse peritoneal macrophages were treated with exendin- 4 at two concentrations (25 and 50 $\mathrm{nmol} / \mathrm{L})$ for $8 \mathrm{~h}$ and then exposed to ox-LDL $(50 \mu \mathrm{g} / \mathrm{mL})$ for $8 \mathrm{~h}$. PDTC $(100 \mu \mathrm{mol} / \mathrm{L})$, a specific NF-KB inhibitor was added $30 \mathrm{~min}$ before ox-LDL stimulation for $8 \mathrm{~h}$. (A) After incubation, migrated cells were observed at a magnification of $\times 400$. (a) 25 nmol/L exendin-4 with $50 \mu \mathrm{g} / \mathrm{mL}$ ox-LDL; (b) $50 \mathrm{nmol} / \mathrm{L}$ exendin- 4 with $50 \mu \mathrm{g} / \mathrm{mL}$ ox-LDL; (c) control; (d) ox-LDL; (e) $100 \mu \mathrm{mol} / \mathrm{L}$ PDTC with $50 \mu \mathrm{g} / \mathrm{mL}$ ox-LDL. (B) All groups of migrated macrophage cells were counted in 10 random visual fields. Data are shown as the mean \pm SEM of three independent experiments. ${ }^{\mathrm{b}} P<0.05$, ${ }^{\mathrm{c}} P<0.01$ vs ox-LDL treated group in 10 visual fields. 
A

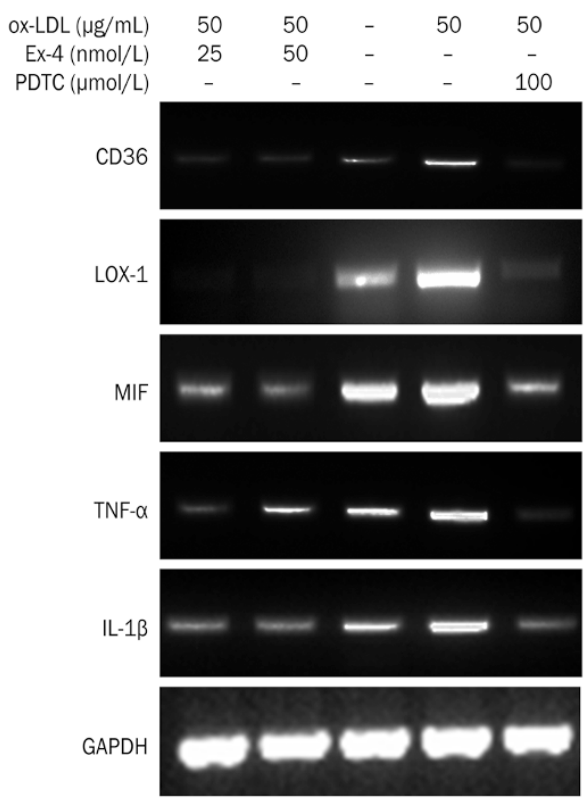

B

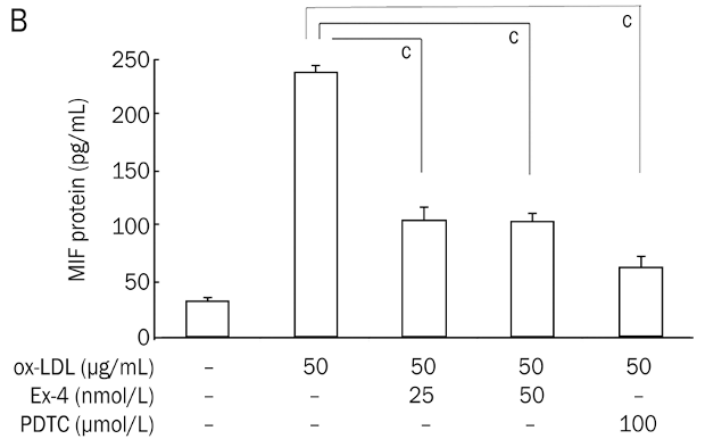

Figure 2. Effect of exendin-4 on the expression of macrophage migrationrelated genes and MIF protein. Mouse peritoneal macrophages were pretreated with exendin- $4(25,50 \mathrm{nmol} / \mathrm{L})$ for $8 \mathrm{~h}$ followed by stimulation with ox-LDL ( $50 \mathrm{mg} / \mathrm{mL}$ ) for $1 \mathrm{~h}$. (A) Semi-quantitative RT-PCR analysis of macrophage migration-related genes. (B) ELISA analysis of MIF protein expression. Data are shown as the mean \pm SEM of three independent experiments. ${ }^{c} P<0.01$ vs ox-LDL treated group.

exendin- 4 treated group. ICAM- 1 mRNA and protein expression was reduced in the treated group (Figure 4A, 4C), as determined by RT-PCR analysis and ELISA, respectively. The mRNA expression of cyclooxygenase 2 (COX-2) and matrix metalloproteinase-2 (MMP-2) also decreased markedly in the exendin-4- and PDTC-treated groups (Figure 4A).

\section{Discussion}

Previous studies of atherosclerotic plaque progression and regression have revealed the dynamic nature of atherosclerotic lesions and the important roles of macrophage trapping in lesion growth and macrophage migration in atherosclerotic plaque regression ${ }^{[6,23]}$. Current research is focused on the CD36-dependent uptake of ox-LDL. This interaction has been shown to be critical to cholesterol accumulation and subsequent foam cell formation ${ }^{[4,23]}$. The binding between ox-LDL and CD36 could also promote the production of ROS, which in turn results in the phosphorylation of Focal Adhesion Kinase (FAK) and consequently inhibits macrophage migration ${ }^{[23]}$. Therefore, certain drugs, such as statins, have been used to treat atherosclerosis by inhibiting the expression of CD36 and the production of $\operatorname{ROS}^{[32]}$. These results demonstrated that ox-LDL-induced inhibition of macrophage migration played important roles in the progression of atherosclerosis.

Exendin-4, a functional analogue of GLP-1, was originally used in the treatment of type 2 diabetes. Subsequent studies revealed that it also played an important role in cardiovascular disease $\mathrm{e}^{[10,14]}$. Recent research has shown that GLP-1 and its receptor agonist exendin-4 can down-regulate the scavenger receptor CD36 by activating the cyclic adenosine monophosphate (cAMP) signaling pathway in macrophages ${ }^{[33]}$. Our present study focused on the effect of exendin-4 on ox-LDLinduced inhibition of macrophage migration and the mechanisms underlying those effects. We have demonstrated that exendin- 4 can suppress the expression of ICAM- 1 and MIF in macrophage cells and consequently relieves the ox-LDLinduced inhibition of macrophage migration. This effect is probably caused by activating the NF-KB pathway. Interestingly, our results also indicate that exendin- 4 can suppress MMP-9 activity in macrophages, which may contribute to inhibition of macrophage infiltration.

As an inducing factor, MIF takes part in macrophage trapping around arterial intima and the forming of foam cells ${ }^{[34]}$, although the expression of MIF may be diminished in the macrophage-derived foam cells and macrophages in advanced atherosclerotic plaques ${ }^{[34]}$. Ox-LDL can inhibit macrophage random migration away from the artery through upregulating MIF, CD36 and scavenger receptor-A (SR-A) ${ }^{[33]}$, resulting in the accumulation of macrophages at the injury site in atherosclerotic lesions. Macrophage recruitment that has been induced by MIF at least partially relies on enhanced expression of some other inflammatory mediators, such as ICAM-1, which inhibits macrophage migration directly ${ }^{[34,35]}$. Our research provides evidence that exendin 4 at $25 \mathrm{nmol} / \mathrm{L}$ and $50 \mathrm{nmol} / \mathrm{L}$ could relieve ox-LDL-induced inhibition of peritoneal macrophage migration, at least partially by regulating ox-LDL receptor CD36 and its downstream regulator MIF. Our results also demonstrate that exendin- 4 can suppress the expression of ICAM-1, which may contribute to the GLP-1 receptor-mediated increase of macrophage migration in vitro. Therefore, exendin- 4 affects major events in the initial stages of atherosclerosis by allowing macrophages to migrate away from the arterial intima and reduce the subsequent plaque formation.

Proteases, including MMP-2 and MMP-9, have been implicated in the degradation of the ECM, leading cells to migrate across the ECM. Interestingly, in the present study, we also found that exendin- 4 can inhibit MMP-9 activity and MMP-9 expression at the transcriptional level. The data suggest that exendin- 4 can also regulate the ability of macrophage infiltration in the ECM via inactivation of MMP-9 ${ }^{[31]}$, which ameliorates the development of atherosclerotic lesions. A previous 
A

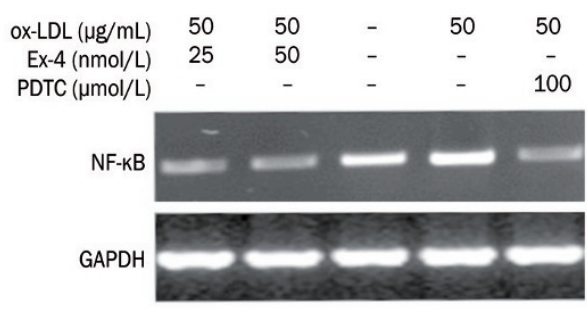

C

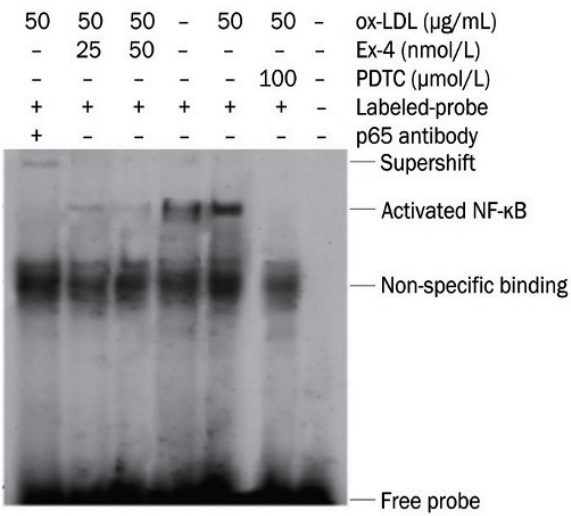

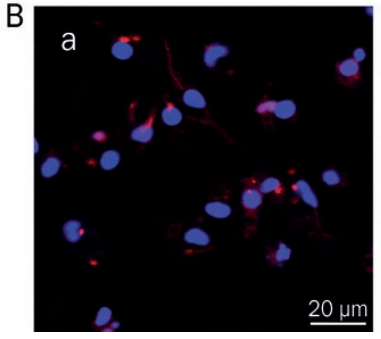
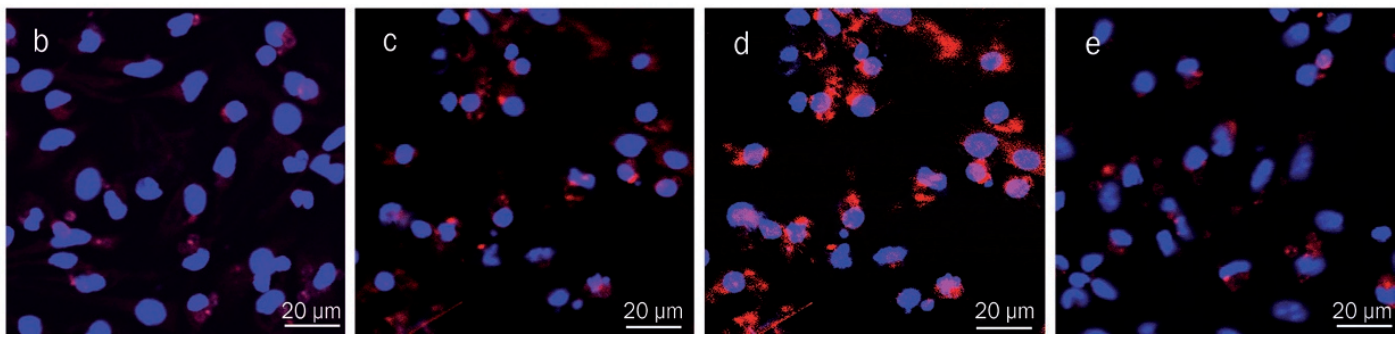

Figure 3. Effect of exendin-4 on ox-LDL-induced NF-KB activation in macrophages. (A) Mouse peritoneal macrophage cells were pretreated with exendin-4 (25, $50 \mathrm{nmol} / \mathrm{L})$ for $8 \mathrm{~h}$ followed by stimulation with ox-LDL (50 $\mu \mathrm{g} / \mathrm{mL})$ for $1 \mathrm{~h}$, and then analyzed by semi-quantitative RT-PCR. (B) Representative confocal immune-fluorescence analysis of mouse peritoneal macrophage cells using rabbit polyclonal antibody against p65 subunit (red). DAPI (blue) was used to counterstain the cell nuclei. Bar=20 $\mu \mathrm{m}$. (a) $25 \mathrm{nmol} / \mathrm{L}$ exendin- 4 with $50 \mu \mathrm{g} / \mathrm{mL}$ ox-LDL; (b) $50 \mathrm{nmol} / \mathrm{L}$ exendin-4 with 50 $\mathrm{gg} / \mathrm{mL}$ ox-LDL; (c) control; (d) ox-LDL; (e) $100 \mu \mathrm{mol} / \mathrm{L}$ PDTC with $50 \mu \mathrm{g} / \mathrm{mL}$ ox-LDL. (C) Electrophoretic mobility shift assay (EMSA).
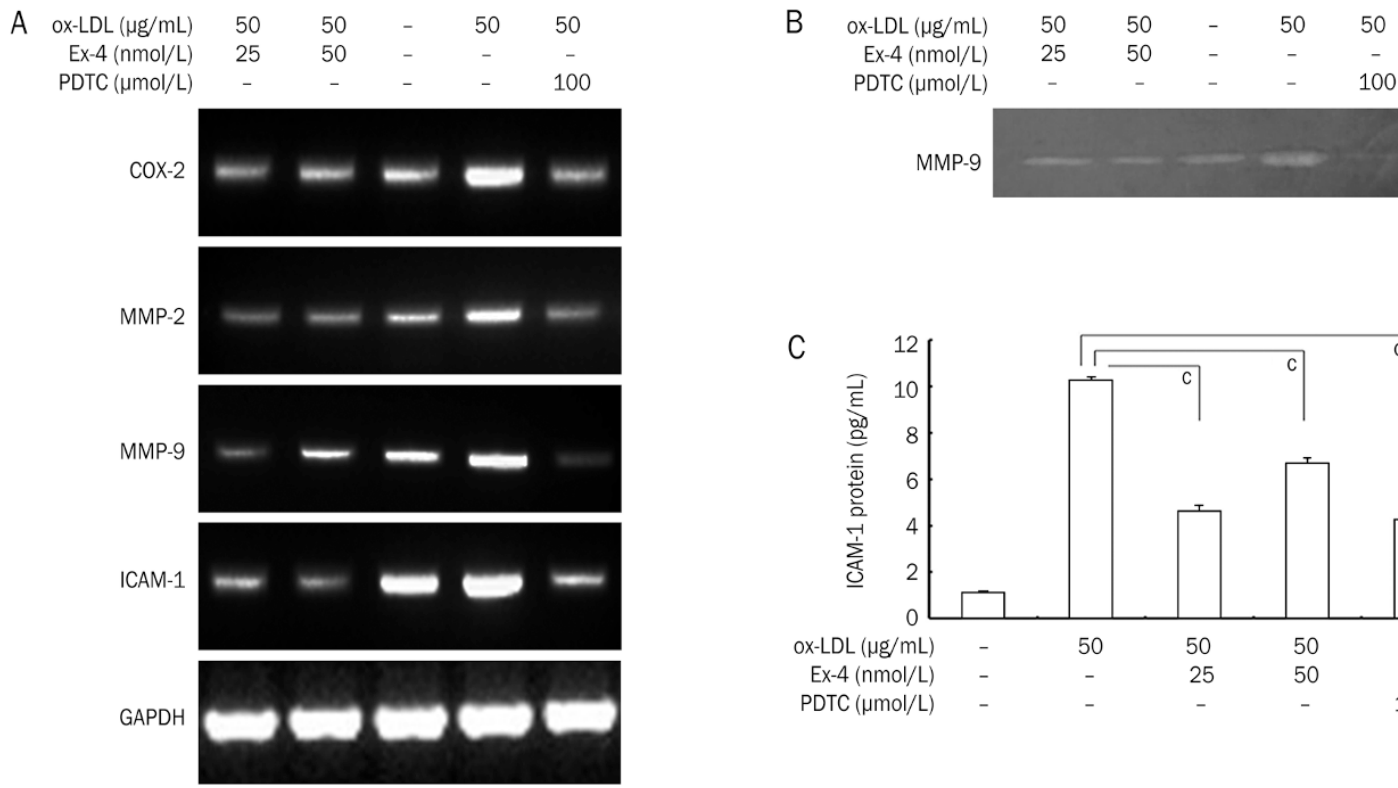

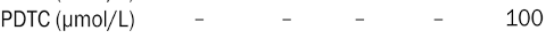
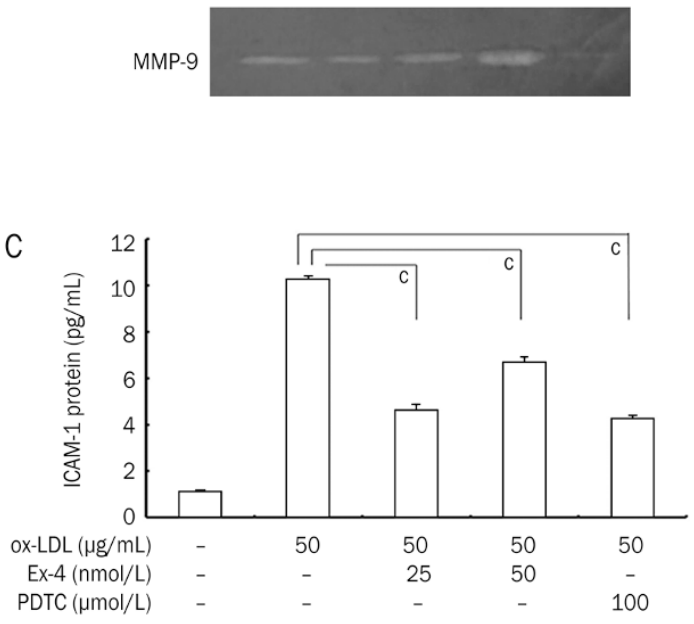

Figure 4. Exendin-4 suppressed the expression of COX-2, MMP-2, MMP-9, and ICAM-1 genes, the activity of MMP-9 and ICAM-1 protein expression. Mouse peritoneal macrophage cells were pretreated with exendin-4 (25 and $50 \mathrm{nmol} / \mathrm{L})$ for $8 \mathrm{~h}$ followed by stimulation with ox-LDL ( $50 \mathrm{mg} / \mathrm{mL})$ for 1 h. (A) Macrophage migration-related genes expression determined by semi-quantitative RT-PCR. (B) MMP-9 activity determined by gelatin zymography. (C) ICAM-1 protein expression as determined by ELISA. Data are shown as the mean \pm SEM of three independent experiments. ${ }^{\mathrm{C}} P<0.01 \mathrm{vs}$ ox-LDL treated group. 
study indicated that the inhibition of MIF may also result in the reduction of MMP-9 activity ${ }^{[36,37]}$. To further explore the molecular mechanisms by which exendin-4 regulates macrophage migration, the NF-kB-specific inhibitor PDTC was tested in our study. Our results revealed that macrophage cells treated with the NF-kB inhibitor migrated more slowly than the untreated cells when, but migrated slightly faster than the cells in the control group. Treatment with ox-LDL inhibited macrophage migration, not only by activating the NF-kB pathway but also through other related pathways. Our results also imply that exendin-4 may broadly affect a variety of intracellular signaling cascades, including the NF-kB signal transduction pathway, which in turn influences the movement of macrophages. Current research shows that CD36 and a proliferator-activated receptor-gamma (PPAR- $\gamma$ ) pathway play important roles in ox-LDL uptake in macrophages ${ }^{[23,38,39]}$. We demonstrated that exendin- 4 reduced the expression of PPAR- $\gamma$ induced by ox-LDL (data not shown). However, the exact action mechanism still requires further investigation.

In conclusion exendin- 4 ameliorates the inhibition of ox-LDL on macrophage migration in vitro, via suppressing ox-LDLinduced expression of ICAM-1 and MIF, which is probably mediated by the NF-kB pathway.

\section{Acknowledgements}

This work was supported by grants from the National Natural Science Foundation of China (81273496 and 81172974), the "Simcere Innovation Fund" (CX11B-004XS), the Project Program of State Key Laboratory of Natural Medicines, China Pharmaceutical University (SKLNMZZ201211), the “333” Project of Jiangsu Province, and the National High Technology Research and Development Program of China (863 Program) (2013AA092901).

\section{Author contribution}

Ge-fei MA, Song CHEN, Xiang-dong GAO, and Wenbing YAO designed the research; Ge-fei MA performed the research; Xiang-dong GAO and Wen-bing YAO contributed new reagents and analytical tools; Ge-fei MA and Song CHEN analyzed data; Ge-fei MA, Song CHEN, and Lei YIN wrote the paper.

\section{References}

1 Celermajer DS, Chow CK, Marijon E, Anstey NM, Woo KS. Cardiovascular disease in the developing world: prevalences, patterns, and the potential of early disease detection. J Am Coll Cardiol 2012; 60: 1207-16.

2 Hansson GK, Robertson AK, Söderberg-Nauclér C. Inflammation and atherosclerosis. Ann Rev Pathol 2006; 1: 297-329.

3 Goyal T, Mitra S, Khaidakov M, Wang X, Singla S, Ding Z, et al. Current concepts of the role of oxidized LDL receptors in atherosclerosis. Curr Atheroscler Rep 2012; 14: 150-9.

4 Park YM, Febbraio M, Silverstein RL. CD36 modulates migration of mouse and human macrophages in response to oxidized LDL and may contribute to macrophage trapping in the arterial intima. J Clin Invest 2009; 119: 136-45.

5 Daoud AS, Jarmolych J, Augustyn JM, Fritz KE. Sequential morphologic studies of regression of advanced atherosclerosis. Arch PatholLab Med 1981; 105: 233-9.

6 Llodrá J, Angeli V, Liu J, Trogan E, Fisher EA, Randolph GJ. Emigration of monocyte-derived cells from atherosclerotic lesions characterizes regressive, but not progressive, plaques. Proc Natl Acad Sci U S A 2004; 101: 11779-84.

7 Wissler RW, Vesselinovitch D. Studies of regression of advanced atherosclerosis in experimental animals and man. Ann N Y Acad Sci 1976; 275: 363-78.

8 Bernink FJ, Timmers L, Diamant M, Scholte M, Beek AM, Appelman Y, et al. Effect of additional treatment with EXenatide in patients with an Acute Myocardial Infarction (EXAMI): study protocol for a randomized controlled trial. Trials 2011; 12: 240.

9 Ban K, Hui S Y, Drucker DJ, Husain M. Cardiovascular consequences of drugs used for the treatment of diabetes: potential promise of incretin-based therapies. J Am Soc Hypertens 2009; 3: 245-59.

10 Ussher JR, Drucker DJ. Cardiovascular biology of the incretin system. Endocr Rev 2012; 33: 187-215.

11 Nikolaidis LA, Mankad S, Sokos GG, Miske G, Shah A, Elahi D, et al. Effects of glucagon-like peptide-1 in patients with acute myocardial infarction and left ventricular dysfunction after successful reperfusion. Circulation 2004; 109: 962-5.

12 Noyan-Ashraf MH, Shikatani EA, Schuiki I, Mukovozov I, Wu J, Husain $\mathrm{M}$, et al. A glucagon-like peptide-1 analog reverses the molecular pathology and cardiac dysfunction of a mouse model of obesity. Circulation 2013; 127: 74-85.

$13 \mathrm{Ng}$ DS, Saw NM. The role of HDL and its modulators in the development of diabetes. Curr Opin Lipidol 2012; 23: 167-8.

14 Arakawa M, Mita T, Azuma K, Ebato C, Goto H, Watada H, et al. Inhibition of monocyte adhesion to endothelial cells and attenuation of atherosclerotic lesion by a glucagon-like peptide- 1 receptor agonist, exendin-4. Diabetes 2010; 59: 1030-7.

15 Burger-Kentischer A, Goebel H, Seiler R, Fraedrich G, Schaefer HE, Ihling $\mathrm{C}$, et al. Expression of macrophage migration inhibitory factor in different stages of human atherosclerosis. Circulation 2002; 105: 1561-6.

16 Larson DF, Horak K. Macrophage migration inhibitory factor: controller of systemic inflammation. Crit Care 2006; 10: 138.

17 Olefsky JM, Glass CK. Macrophages, inflammation, and insulin resistance. Ann Rev Physiol 2010; 72: 219-46.

18 Libby P, Lee RT. Matrix matters. Circulation 2000; 102: 1874-6.

19 Schmeisser A, Marquetant R, Illmer T, Graffy C, Garlichs CD, Strasser $\mathrm{RH}$, et al. The expression of macrophage migration inhibitory factor 1alpha (MIF 1alpha) in human atherosclerotic plaques is induced by different proatherogenic stimuli and associated with plaque instability. Atherosclerosis 2005; 178: 83-94.

20 Khan S, Shin EM, Choi RJ, Jung YH, Kim J, Tosun A, et al. Suppression of LPS-induced inflammatory and NF-KB responses by anomalin in RAW 264.7 macrophages. J Cell Biochem 2011; 112: 2179-88.

21 Knapinska A, Fields GB. Chemical biology for understanding matrix metalloproteinase function. Chembiochem 2012; 13: 2002-20.

22 Molloy KJ, Thompson MM, Schwalbe EC, Bell PR, Naylor AR, Loftus IM. Comparison of levels of matrix metalloproteinases, tissue inhibitor of metalloproteinases, interleukins, and tissue necrosis factor in carotid endarterectomy specimens from patients on versus not on statins preoperatively. Am J Cardiol 2004; 94: 144-6.

23 Toth M, Sohail A, Fridman R. Assessment of gelatinases (MMP-2 and MMP-9) by gelatin zymography. Methods Mol Biol 2012; 878: 12135.

24 Sturge J, Todd SK, Kogianni G, McCarthy A, Isacke CM. Mannose receptor regulation of macrophage cell migration. J Leukoc Biol 2007; 
82: 585-93.

25 Shin EM, Zhou HY, Guo LY, Kim JA, Lee HL, Merfort I, et al. Antiinflammatory effects of glycyrol isolated from $G$ uralensis in LPSinduced macrophages. Int Immunopharmacol 2008; 8: 1524-32.

26 Park YM, Febbraio M, Silverstein RL. CD36 modulates migration of mouse and human macrophages in response to oxidized LDL and may contribute to macrophage trapping in the arterial intima. J Clin Invest 2009; 119: 136-45.

27 Cao C, Lawrence DA, Strickland DK, Zhang L. A specific role of integrin Mac-1 in accelerated macrophage efflux to the lymphatics. Blood 2005; 106: 3234-41.

28 Silverstein RL, Li W, Park YM, Rahaman SO. Hanisms of cell signaling by the scavenger receptor CD36: implications in atherosclerosis and thrombosis. Trans Am Clin Climatol Assoc 2010; 121: 206-20.

29 Condon JC, Jeyasuria P, Faust JM, Mendelson CR. Surfactant protein secreted by the maturing mouse fetal lung acts as a hormone that signals the initiation of parturition. Proc Natl Acad Sci U S A 2004; 101: 4978-83.

30 de Groot D, Haverslag RT, Pasterkamp G, de Kleijn DP, Hoefer IE. Targeted deletion of the inhibitory NF-kappaB p50 subunit in bone marrow-derived cells improves collateral growth after arterial occlusion. Cardiovasc Res 2010; 88: 179-85.

31 Hansson GK, Hermansson A. The immune system in atherosclerosis. Nat Immunol 2011; 12: 204-12.

32 Permana PA, Menge C, Reaven PD. Macrophage-secreted factors induce adipocyte inflammation and insulin resistance. Biochem Biophys Res Commun 2006; 341: 507-14.
33 Gong Y, Hart E, Shchurin A, Hoover-Plow J. Inflammatory macrophage migration requires MMP-9 activation by plasminogen in mice. J Clin Invest 2008; 118: 3012-24.

34 Hofnagel O, Luechtenborg B, Weissen-Plenz G, Robenek H. Statins and foam cell formation: impact on LDL oxidation and uptake of oxidized lipoproteins via scavenger receptors. Biochim Biophys Acta 2007; 1771: 1117-24.

35 Nagashima M, Watanabe T, Terasaki M, Tomoyasu M, Nohtomi K, Hirano T, et al. Native incretins prevent the development of atherosclerotic lesions in apolipoprotein $\mathrm{E}$ knockout mice. Diabetologia 2011; 54: 2649-59.

36 Asare Y, Schmitt M, Bernhagen J. The vascular biology of macrophage migration inhibitory factor (MIF). Expression and effects in inflammation, atherogenesis and angiogenesis. Thromb Haemost 2013; 109: 391-8.

37 Kong YZ, Yu X, Tang JJ, Ouyang X, Huang XR, Fingerle-Rowson G, et al. Macrophage migration inhibitory factor induces MMP-9 expression: implications for destabilization of human atherosclerotic plaques. Atherosclerosis 2005; 178: 207-15.

38 Robker RL, Collins RG, Beaudet AL, Mersmann HJ, Smith CW. Leukocyte migration in adipose tissue of mice null for ICAM-1 and Mac-1 adhesion receptors. Obes Res 2004; 12: 936-40.

39 Sueyoshi S, Mitsumata M, Kusumi Y, Niihashi M, Esumi M, Sakurai I, et al. Increased expression of peroxisome proliferator-activated receptor (PPAR)-alpha and PPAR-gamma in human atherosclerosis. Pathol Res Pract 2010; 206: 429-38. 